\title{
Some general features of limited coalescence in solid-stabilized emulsions
}

S. Arditty ${ }^{1}$, C.P. Whitby ${ }^{2}$, B.P. Binks ${ }^{2}$, V. Schmitt ${ }^{1}$, and F. Leal-Calderon ${ }^{3, \text { a }}$

1 Centre de Recherche Paul Pascal, CNRS, Av. A. Schweitzer, 33600 Pessac, France

2 Surfactant \& Colloid Group, Department of Chemistry, University of Hull, Hull, HU6 7RX, UK

3 Laboratoire des Milieux Dispersés Alimentaires, ISTAB, Université Bordeaux 1, Av. des Facultés, 33400 Talence, France

Received 2 September 2003 /

Published online: 21 November 2003 - C EDP Sciences / Società Italiana di Fisica / Springer-Verlag 2003

Eur. Phys. J. E 11, 273-281 (2003)

In Figure 9 the $Y$-axis values are not correct. They must be multiplied by $10^{6}$.

We publish hereunder the corrected figure.

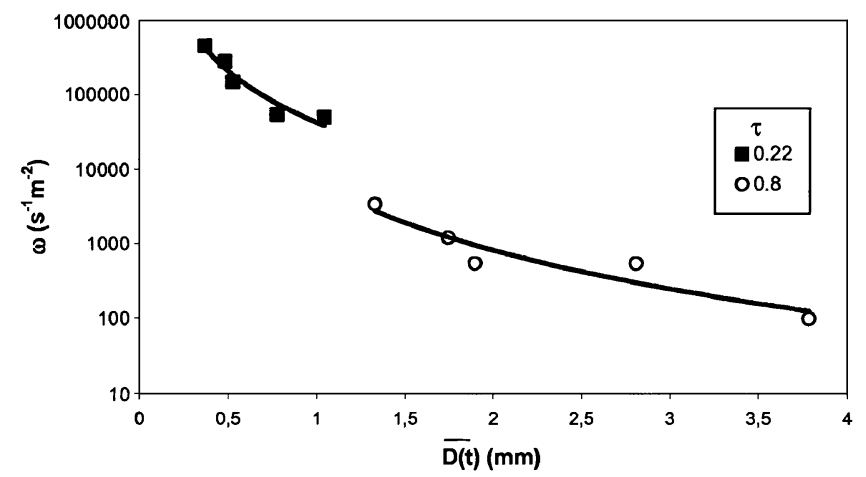

Fig. 9. Variation of the coalescence frequency $\omega$ with $\bar{D}(t)$ at constant $\tau$ (given) for o/w emulsions stabilized by S1 particles. The lines are only guides to the eyes.

\footnotetext{
${ }^{a}$ e-mail: f.leal@istab.u-bordeaux1.fr
} 